Case Reports in
Gastroenterology
Case Rep Gastroenterol 2021;15:225-231

DOI: $10.1159 / 000511250$

Published online: February 18, 2021

(C) 2021 The Author(s)

Published by S. Karger AG, Basel

www.karger.com/crg

This article is licensed under the Creative Commons Attribution-NonCommercial 4.0 International License (CC BY-NC) (http://www.karger.com/Services/OpenAccessLicense).

Usage and distribution for commercial purposes requires written permission.

\title{
Successful Enucleation of a Large Pancreatic Head Schwannoma
}

\author{
Tomoyuki Yamaguchi Shoji Oura Shinichiro Makimoto \\ Department of Surgery, Kishiwada Tokushukai Hospital, Kishiwada-City, Japan
}

\section{Keywords}

Pancreatic duct stenting · Pancreatic schwannoma · Polyglycolic acid sheet · Tumor enucleation

\begin{abstract}
A presumed benign cystic tumor in the pancreatic head had been pointed out to a 78-yearold man 4 years ago. In addition to no communication between the tumor and the main pancreatic duct, magnetic resonance imaging showed that the cystic fluid was serous. Gradual tumor enlargement from 2.1 to $4.0 \mathrm{~cm}$ urged us to resect the tumor. In order to safely enucleate the tumor, we preoperatively placed a pancreatic duct stent and covered the pancreatic parenchyma with a polyglycolic acid sheet, fibrin glue, and thrombin after tumor enucleation. The patient postoperatively developed grade B pancreatic fistula but recovered with antibiotics therapy. Postoperative computed tomography showed successful preservation of the main pancreatic duct. Pathological study showed a well-defined tumor mainly composed of loosely textured and S-100-positive spindle cells with abundant and hyalinized blood vessels in the cystic walls with palisading spindle cells, leading to the diagnosis of Antoni B schwannoma. The patient was discharged on the 11th day after operation. Both pancreatic duct stunting and covering the exposed pancreatic parenchyma with a polyglycolic acid sheet, fibrin glue, and thrombin are feasible measures to enucleate large benign tumors in the pancreatic head.
\end{abstract}




\section{Case Reports in Gastroenterology}

Case Rep Gastroenterol 2021;15:225-231

DOI: $10.1159 / 000511250$

(c) 2021 The Author(s). Published by S. Karger AG, Basel www.karger.com/crg

Yamaguchi et al.: Successful Enucleation of a Large Pancreatic Head Schwannoma

\section{Introduction}

Widespread use of cross-sectional imaging has facilitated the diagnosis of pancreatic tumors in patients without any symptoms. In addition, multidetector-row computed tomography (CT) and magnetic resonance imaging (MRI) have enabled us to evaluate the shape, size, site, and even gross configuration (e.g., intraductal, cystic, or solid) of pancreatic tumors, leading to the possible observation of presumed benign pancreatic tumors without immediate surgical intervention.

Schwannomas are benign tumors comprised of neoplastic Schwann cells, mainly arising from cranial, spinal, or peripheral nerves [1]. Patients generally present a soft tissue mass with no symptoms or with various symptoms, based on the affected nerves and tumor size, such as hearing loss, tinnitus, facial numbness, pain, focal neurological findings, or mass effect. Preoperative diagnosis, however, is often difficult due to the lack of characteristic image findings of schwannomas.

Here, we report an extremely rare case of a large schwannoma in the pancreatic head, being successfully treated both with tumor enucleation after pancreatic duct stenting and a unique stump measure.

\section{Case Report}

A 78-year-old man with a presumed benign cystic pancreatic tumor was referred to our hospital. CT showed a well-defined oval cystic mass, $21 \times 20 \mathrm{~mm}$ in size. Follow-up CTs showed gradual tumor enlargement, i.e., $40 \times 34 \mathrm{~mm}$, in 4 years (Fig. 1). MRI also showed a mass with hypointensity on T1-weighted image and marked hyperintensity on T2-weighted image (Fig. 2), suggesting the presence of serous fluid in the tumor. Positron emission tomography/CT showed a slight accumulation (standardized uptake value max. of 2.0) in the tumor. Magnetic resonance cholangiopancreatography showed no communication between the tumor and the main pancreatic duct (Fig. 2), negating the diagnosis of pancreatic intraductal papillary mucinous neoplasm (IPMN). Endoscopic ultrasound (EUS) showed an oval cystic mass with septal walls. Due to the tumor enlargement, we then judged the tumor should be pathologically examined under the presumed diagnosis of serous neoplasm (SN) or some other benign neoplasm of the pancreas. To safely enucleate the tumor, we preoperatively placed a pancreatic duct stent. In the operation, we found the tumor to be adhering to but surgically detachable from the duodenum and omentum. We successfully enucleated the tumor without macroscopically damaging both the cystic wall and the pancreatic main duct. To further prevent postoperative pancreatic fistula, we covered the exposed pancreatic parenchyma with a polyglycolic acid sheet, fibrin glue, and thrombin after tumor enucleation. Postoperative pathological study showed a well-defined tumor mainly composed of loosely textured spindle cells with abundant and hyalinized blood vessels in the cystic walls with palisading spindle cells. Immunohistochemical studies showed extremely high positivity of S-100 and negativity of CD117, CD34, DOG-1, caldesmon, and SMA, leading to the diagnosis of Antoni B type schwannoma of the pancreas (Fig. 3). Moderate pancreatic fistula, i.e., International Study Group on Pancreatic Fistula (ISGPF) Grade B, was observed but successfully managed with antibiotics administration. Postoperative abdominal CT showed that the main pancreatic duct, though being very close to the resection stump, was safely preserved. The patient was discharged on the 11th day after the operation and complained of no symptoms for 3 months.

\section{Karger'=}




\section{Case Reports in Gastroenterology}

Case Rep Gastroenterol 2021;15:225-231

DOI: $10.1159 / 000511250$

(c) 2021 The Author(s). Published by S. Karger AG, Basel www.karger.com/crg

Yamaguchi et al.: Successful Enucleation of a Large Pancreatic Head Schwannoma

\section{Discussion}

Cystic components can be seen in various diseases of the pancreas, such as acinar cystic transformation, SN, mucinous cystic neoplasm, and IPMN. As magnetic resonance cholangiopancreatography clearly showed no communication between the pancreatic main duct and the tumor, we could easily exclude the possibility of IPMN [2]. In addition, due to the intensity patterns on MRI, we could evaluate the fluid in the presumed cystic tumor not as mucinous but as serous. We, therefore, could also exclude the possibility of mucinous cystic neoplasm preoperatively. Acinar cystic transformation generally predominates in females and forms multilocular cystic masses but can also occur in males and form unilocular cystic masses [3]. SNs of the pancreas tend to arise in the pancreatic body and tail but can occur anywhere in the pancreas. In addition, SNs generally present with a solitary mass but can also present with multilocular masses [4].

EUS-guided fine needle aspiration (FNA) is a useful modality for obtaining a tissue diagnosis [5] and seemed to be an attractive measure in this case. We, however, did not perform EUS-guided FNA in this case due to the following two reasons. Firstly, negative study of EUSguided FNA could not rule out the presence of malignant foci in the tumor. Secondly, enlarging tumor implied the high pressure of the cystic portion, leading to the possible dissemination of malignant cells, if present. Compared to mucinous cystic neoplasms of the pancreas, malignant SNs are extraordinarily rare, but serous cystadenocarcinomas have been reported [6]. We, therefore, were forced to move on to surgical pathologic study.

In the gastrointestinal organs, schwannomas are far more prevalent in the stomach and rare in the esophagus, colon, and rectum [7]. Pancreatic schwannoma is extremely rare and lacks typical clinical features and imaging findings except for the sharp delineation from the adjacent tissue or organs. Cystic formation, often seen in Antoni B schwannoma, and tumor enlargement made it difficult to diagnose and treat the presumably benign tumor. In addition, tumor size and location further complicated the resection of the tumor.

Less invasive surgeries, i.e., distal (subtotal) pancreatectomy and central pancreatectomy $[8,9]$, are feasible approaches to pancreatic tumors in the pancreatic body or tail. Pancreaticoduodenectomy (PD) is a standard technique for tumors in the pancreatic head except for small and pedunculated, i.e., easily resectable, benign tumors. An eventful postoperative course was reported in a case of pancreatic head schwannoma treated with PD using a standard Whipple procedure [10]. We, therefore, initially planned enucleation followed by PD as a second operation just in case of histologically proven malignant tumor on routine histological evaluation. Enucleation of large tumors in the pancreatic head naturally leads to high possibility of damaging the main pancreatic duct. Preoperative pancreatic duct stenting enabled us to exactly identify the pancreatic duct, leading to the safer preservation of the main pancreatic duct. Covering the exposed parenchyma using a polyglycolic acid sheet, fibrin glue, and thrombin is often performed in lung operations, effectively preventing postoperative air leakage [11]. Both preoperative pancreatic duct stenting and covering the exposed pancreatic parenchyma with these materials are very useful measures to enucleate large presumably benign tumors in the pancreatic head.

In conclusion, an extremely rare case of large pancreatic head schwannoma was successfully diagnosed and treated with enucleation. Pancreatic main duct stenting and parenchymal covering using a polyglycolic acid sheet are useful measures to enucleate large benign tumors in the pancreatic head. Further studies are warranted to evaluate our enucleation techniques for presumably benign but pathologic study-requiring larger tumors in the pancreatic head.

\section{Karger'=}




\section{Case Reports in Gastroenterology}

\begin{tabular}{l|l}
\hline DOI: 10.1159/000511250 & ○ 2021 The Author(s). Published by S. Karger AG, Basel
\end{tabular} www.karger.com/crg

Yamaguchi et al.: Successful Enucleation of a Large Pancreatic Head Schwannoma

\section{Statement of Ethics}

We have reported this case in compliance with the Declaration of Helsinki. Informed written consent was obtained from the patient for the publication of the clinical data including images.

\section{Conflict of Interest Statement}

The authors have no conflicts of interest to declare.

\section{Funding Sources}

No funding was received for this research.

\section{Author Contributions}

T. Yamaguchi contributed the design of the report. S. Oura drafted the manuscript. S. Makimoto revised the manuscript. All authors have read and approved the final version of the manuscript.

\section{References}

1 Perry A, Jo VY. Schwannoma. In: WHO classification of tumours. 5th ed. Vol 3. Soft tissue and bone tumours. Geneva: World Health Organization; 2020. p. 226-31.

2 Grützmann R, Niedergethmann M, Pilarsky C, Klöppel G, Saeger HD. Intraductal papillary mucinous tumors of the pancreas: biology, diagnosis, and treatment. Oncologist. 2010;15(12):1294-309.

3 Zamboni G, Terris B, Scarpa A, Kosmahl M, Capelli P, Klimstra DS, et al. Acinar cell cystadenoma of the pancreas: a new entity? Am J Surg Pathol. 2002 Jun;26(6):698-704.

4 Khashab MA, Shin EJ, Amateau S, Canto MI, Hruban RH, Fishman EK, et al. Tumor size and location correlate with behavior of pancreatic serous cystic neoplasms. Am J Gastroenterol. 2011 Aug;106(8):1521-6.

5 Turner BG, Cizginer S, Agarwal D, Yang J, Pitman MB, Brugge WR. Diagnosis of pancreatic neoplasia with EUS and FNA: a report of accuracy. Gastrointest Endosc. 2010 Jan;71(1):91-8.

6 Jais B, Rebours V, Malleo G, Salvia R, Fontana M, Maggino L, et al. Serous cystic neoplasm of the pancreas: a multinational study of 2622 patients under the auspices of the International Association of Pancreatology and European Pancreatic Club (European Study Group on Cystic Tumors of the Pancreas). Gut. 2016 Feb;65(2):305-12.

7 Antonescu CR, Hornick JL. Schwannoma. In: WHO classification of tumours. 5th ed. Vol 1. Digestive system tumours. Geneva: World Health Organization; 2019. p. 477-8.

8 Xu SY, Wu YS, Li JH, Sun K, Hu ZH, Zheng SS, et al. Successful treatment of a pancreatic schwannoma by spleen-preserving distal pancreatectomy. World J Gastroenterol. 2017 May;23(20):3744-51.

9 Xu SY, Sun K, Owusu-Ansah KG, Xie HY, Zhou L, Zheng SS, et al. Central pancreatectomy for pancreatic schwannoma: A case report and literature review. World J Gastroenterol. 2016 Oct;22(37):8439-46.

10 Ercan M, Aziret M, Bal A, Șentürk A, Karaman K, Kahyaoğlu Z, et al. Pancreatic schwannoma: A rare case and a brief literature review. Int J Surg Case Rep. 2016;22:101-4.

11 Ozawa Y, Sakai M, Ichimura H. Covering the staple line with polyglycolic acid sheet versus oxidized regenerated cellulose mesh after thoracoscopic bullectomy for primary spontaneous pneumothorax. Gen Thorac Cardiovasc Surg. 2018 Jul;66(7):419-24. 
Case Reports in Gastroenterology
Case Rep Gastroenterol 2021;15:225-231

DOI: $10.1159 / 000511250$

(c) 2021 The Author(s). Published by S. Karger AG, Basel www.karger.com/crg

Yamaguchi et al.: Successful Enucleation of a Large Pancreatic Head Schwannoma
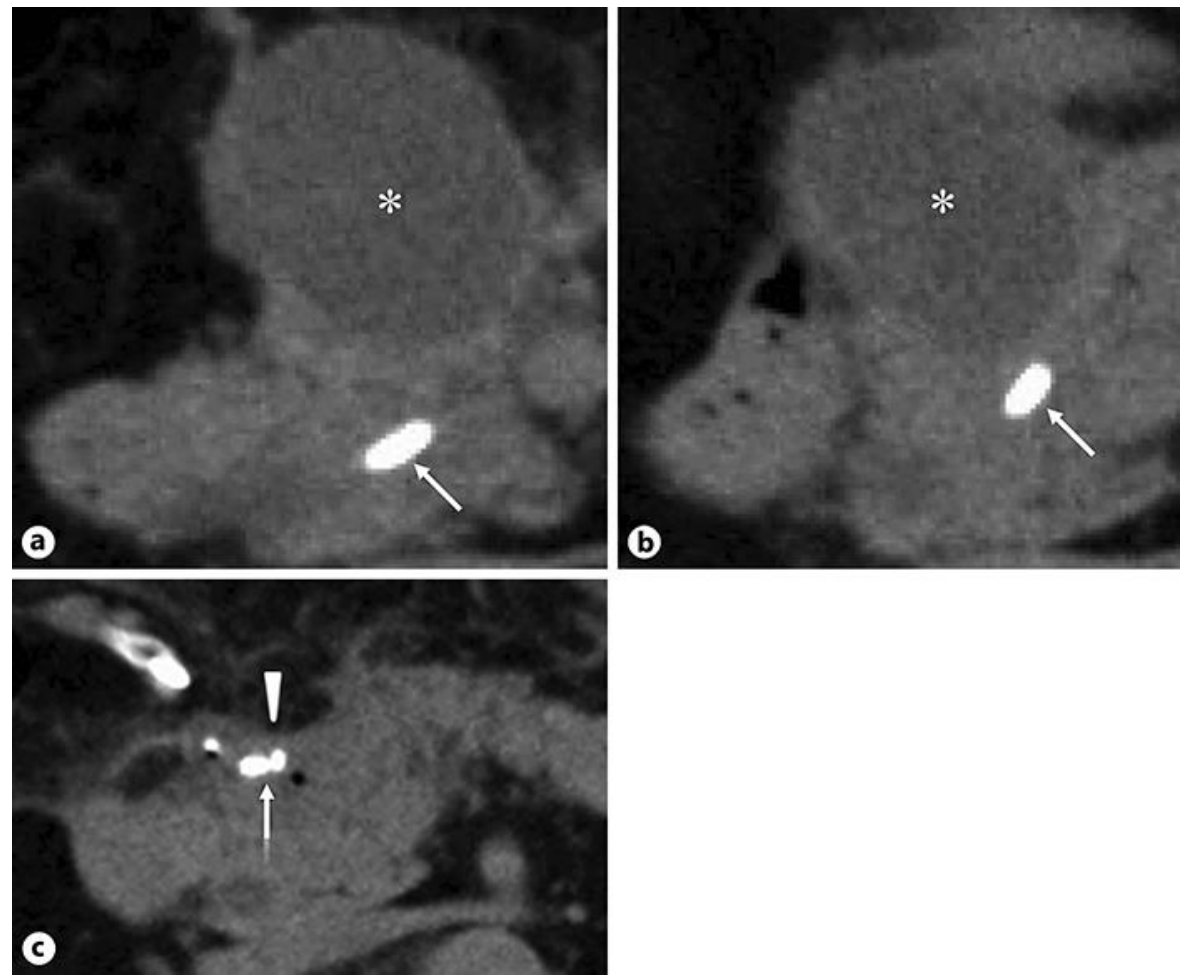

Fig. 1. Computed tomography (CT) around the pancreas. a, b Preoperative CT showed an oval cystic mass (asterisk) very close to the pancreatic duct stent (arrows). c Postoperative CT showed successful enucleation of the tumor without pancreatic duct damage. Resection stump (arrowhead) was very close to the stent (arrow). 
Case Reports in Gastroenterology
Case Rep Gastroenterol 2021;15:225-231

DOI: $10.1159 / 000511250$

๑ 2021 The Author(s). Published by S. Karger AG, Basel www.karger.com/crg

Yamaguchi et al.: Successful Enucleation of a Large Pancreatic Head Schwannoma
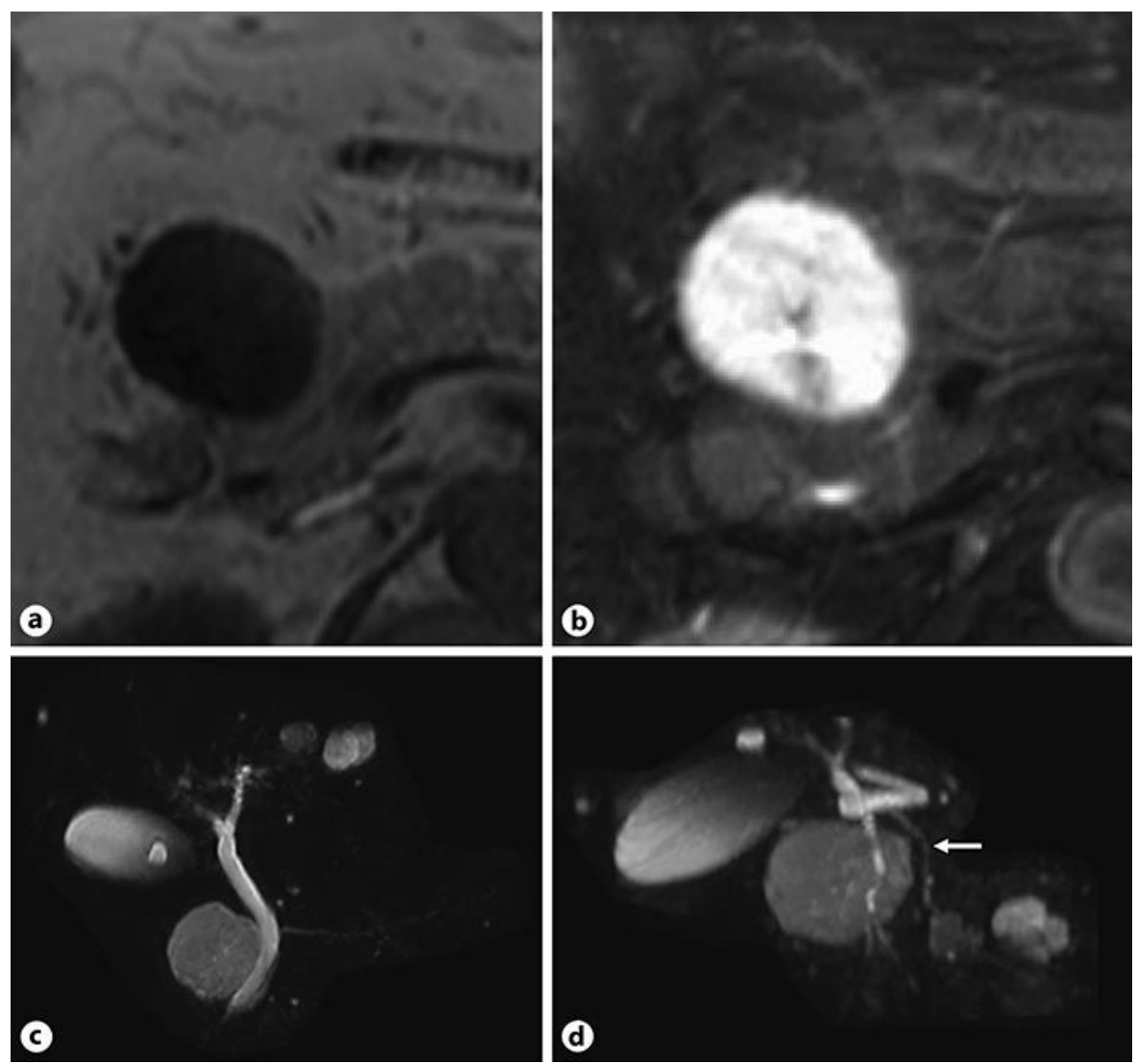

Fig. 2. Magnetic resonance imaging (MRI) of the tumor and correlation between the tumor and main pancreatic duct. MRI showed an oval mass with low intensity on T1-weighted image (a) and very high intensity on T2-weighted image (b). Magnetic resonance cholangiopancreatography showed liver cysts, gall bladder, bile duct, main pancreatic duct, and the tumor on a frontal view (c) and no communication between the tumor and the main pancreatic duct on a rotated view (d). 

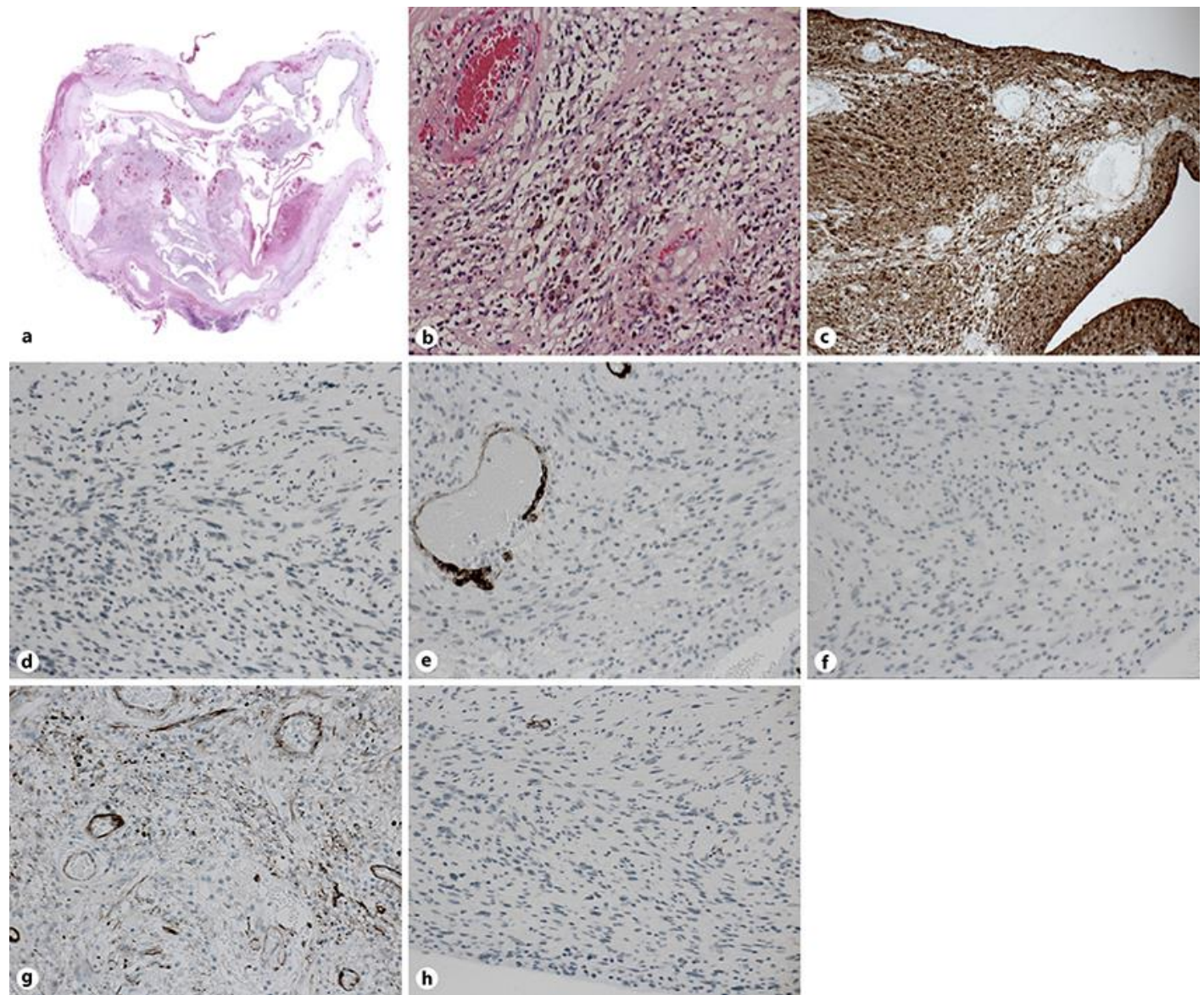

Fig. 3. Pathological findings. Low-magnification view (a) showed a collapsed tumor with cystic part. High magnification view $(b, \mathrm{HE}, \times 200)$ showed loosely textured spindle cells with hyalinized vessels and high S100 positivity $(\mathbf{c}, \times 200)$ and CD117 (d, $\times 200)$, CD34 (e, $\times 200)$, DOG-1 (f, $\times 200)$, caldesmon $(\mathbf{g}, \times 200)$, and SMA $(h, \times 200)$ negativity. 